\title{
VEGETATION AND FIRE: FEEDBACKS TO PLIOCENE ARCTIC CLIMATE
}

Presenting Author: Tamara Fletcher

Co-authors: Feng, R., Brown, K., Warden, L., Sinninghe Damste, J., Csank, A., Higuera, P., Rybczynski, N., Otto-Bliesner, B., Ballantyne, A. 


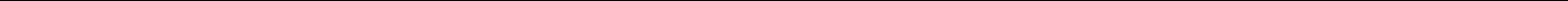




\section{Strathcona Fjord}

by George Rinaldino Teichmann 2004

reproduced courtesy of Canadian Museum of Nature

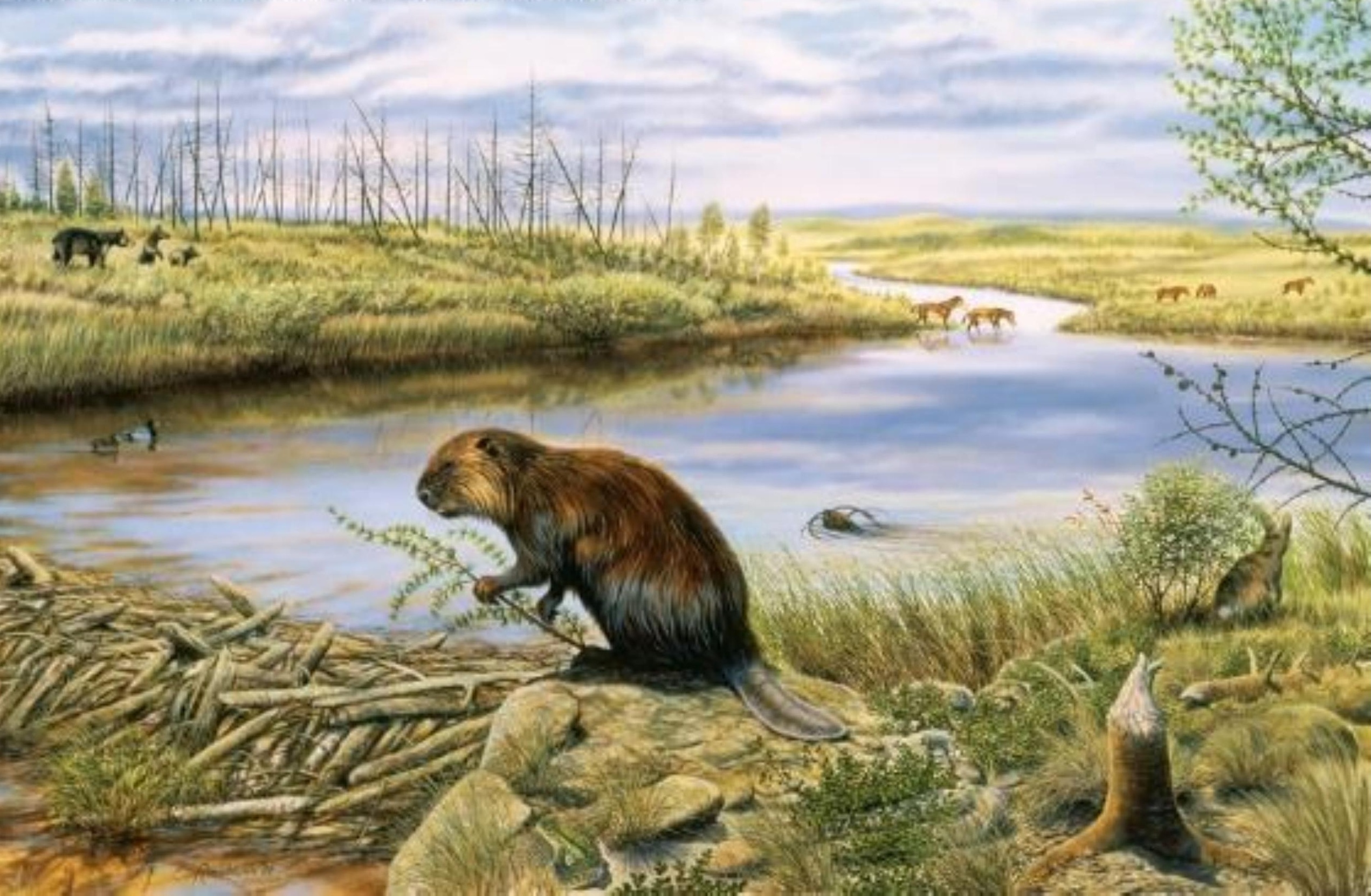




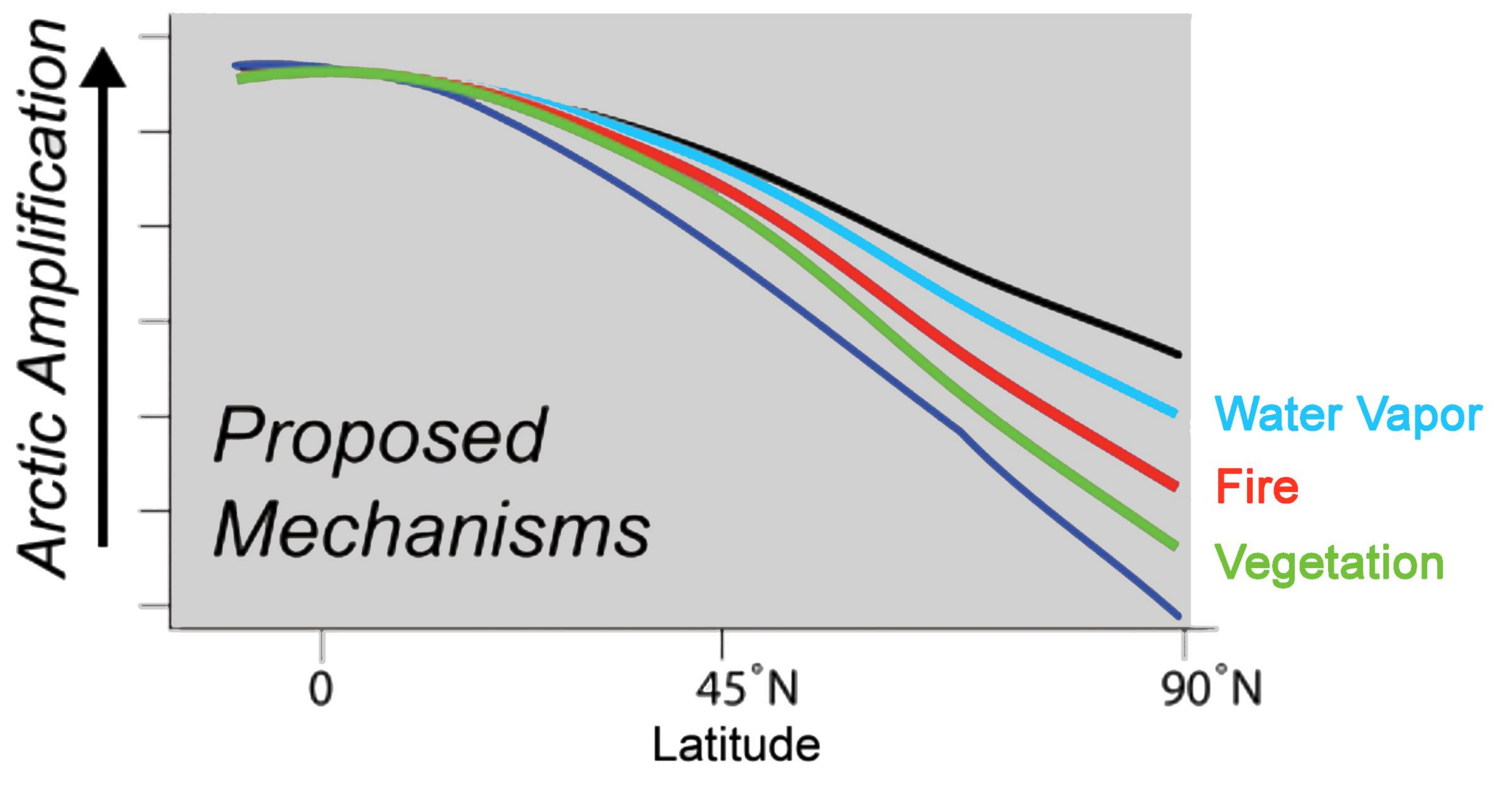




\section{Approach}

1. Improve spatial and temporal resolution of proxies for climate in the Pliocene Canadian Arctic Archipelago (PCAA)

2. Investigate the Pliocene Arctic fire regime across the PCAA

3. Explore vegetation-fire relationships in the PCAA

4. Model the influence of fire as a mechanism for Arctic amplification of temperature using the Community Earth System Model from NCAR 
Meighen Island MI-1 \& MI-2

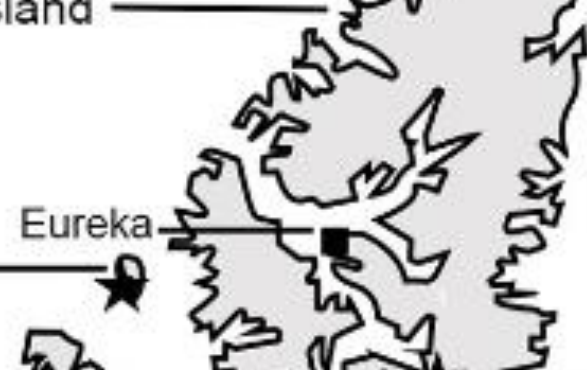

$75^{\circ} \mathrm{N}$

ज्ञात एव हु हो
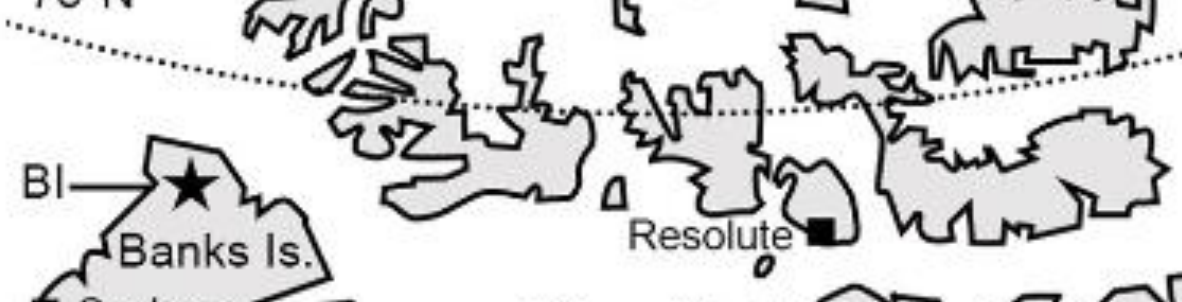

Baffin Bay
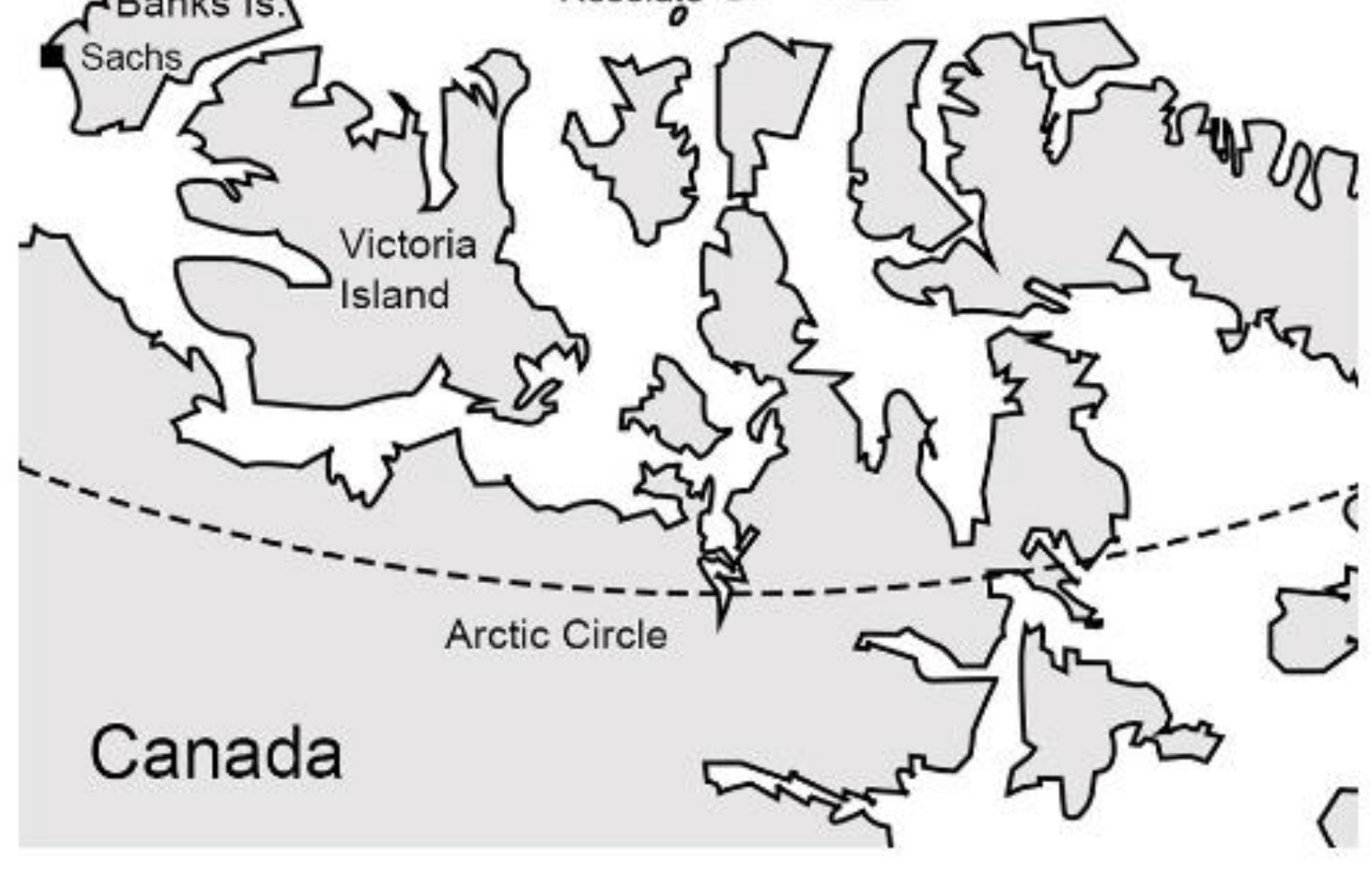

Fletcher et al. 2017 


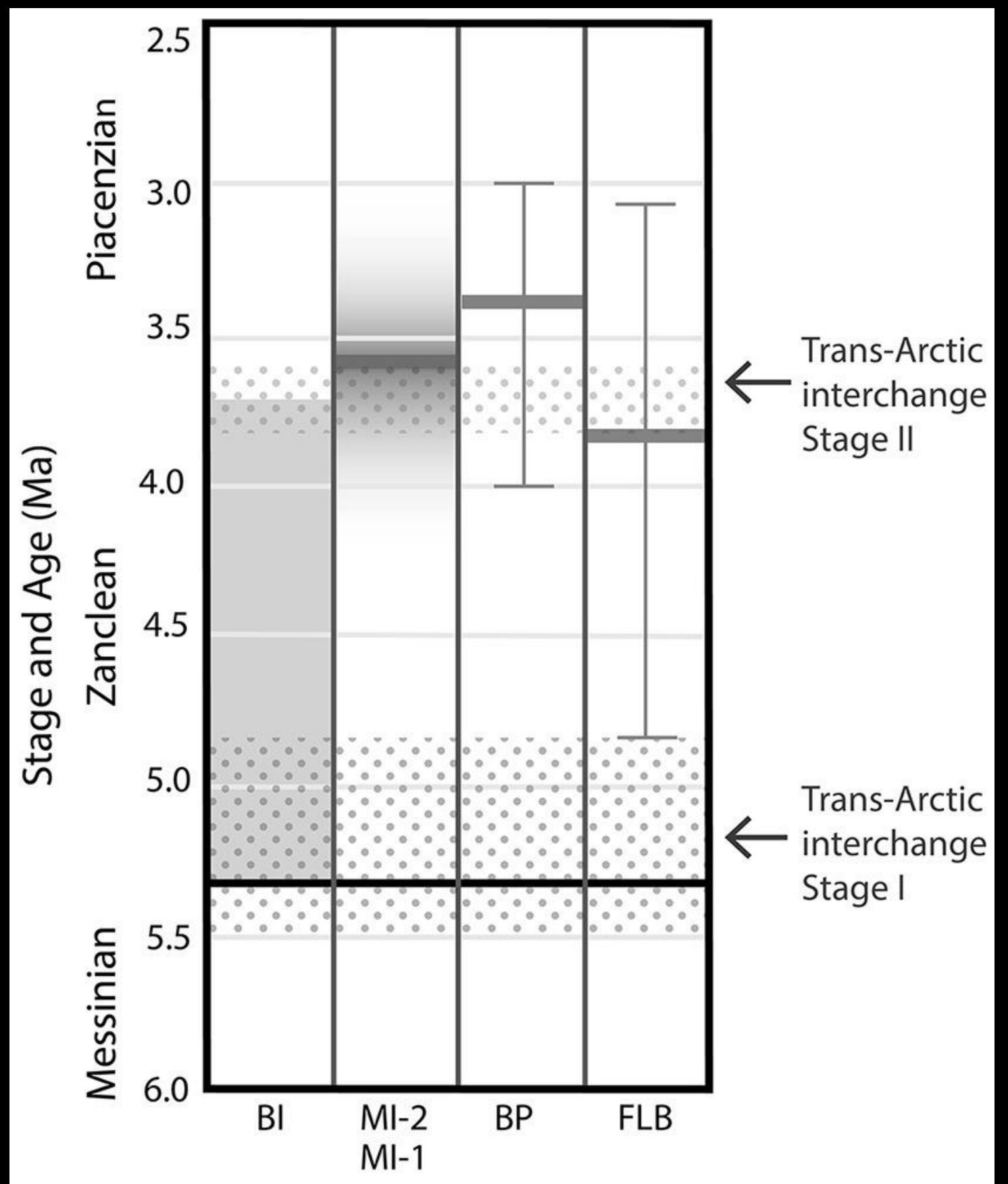

Fletcher et al. 2017 


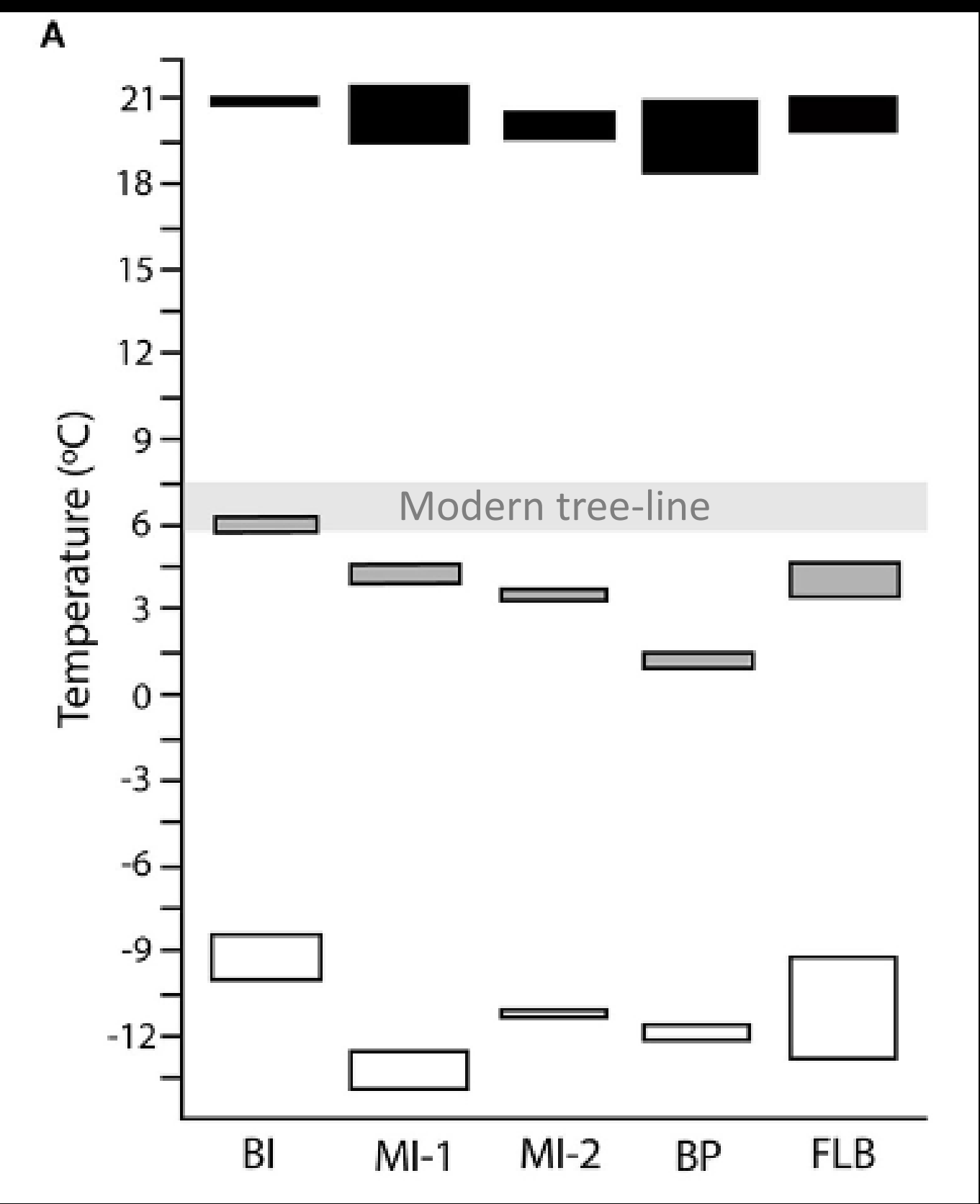

Maximum temperature of the warmest month

Mean annual air temperature

Minimum temperature of the coolest month 


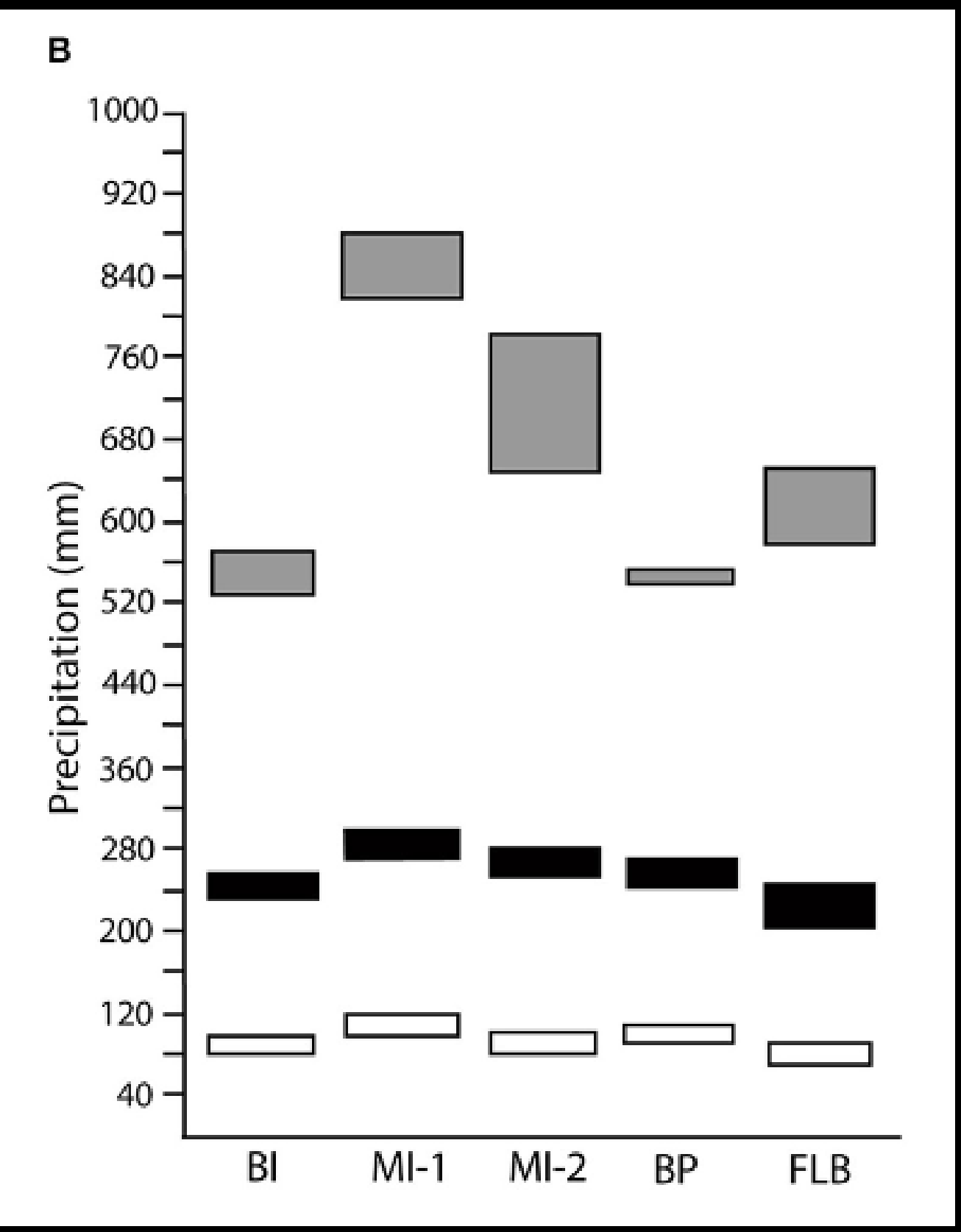

Mean annual precipitation

Precipitation of the wettest quarter

Precipitation of the driest quarter 


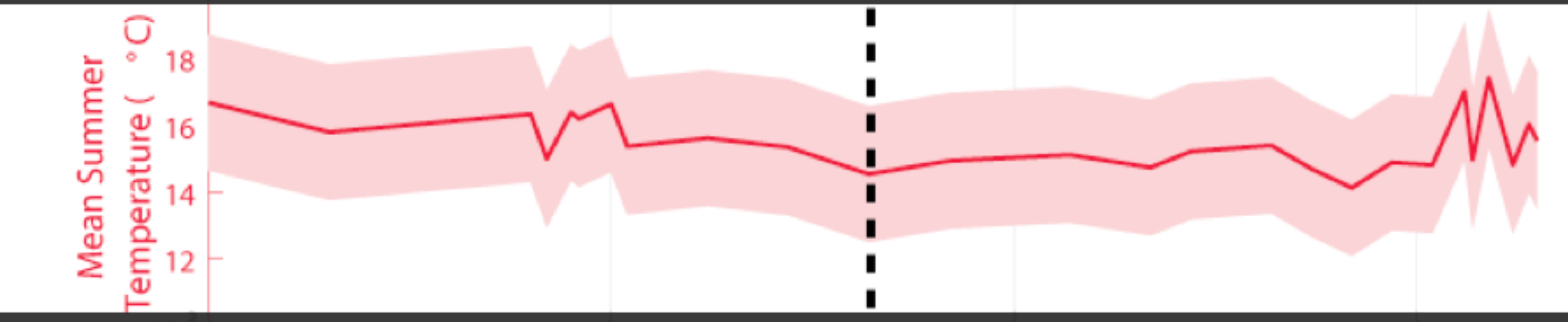

Preliminary data:

Fletcher et al. in prep 


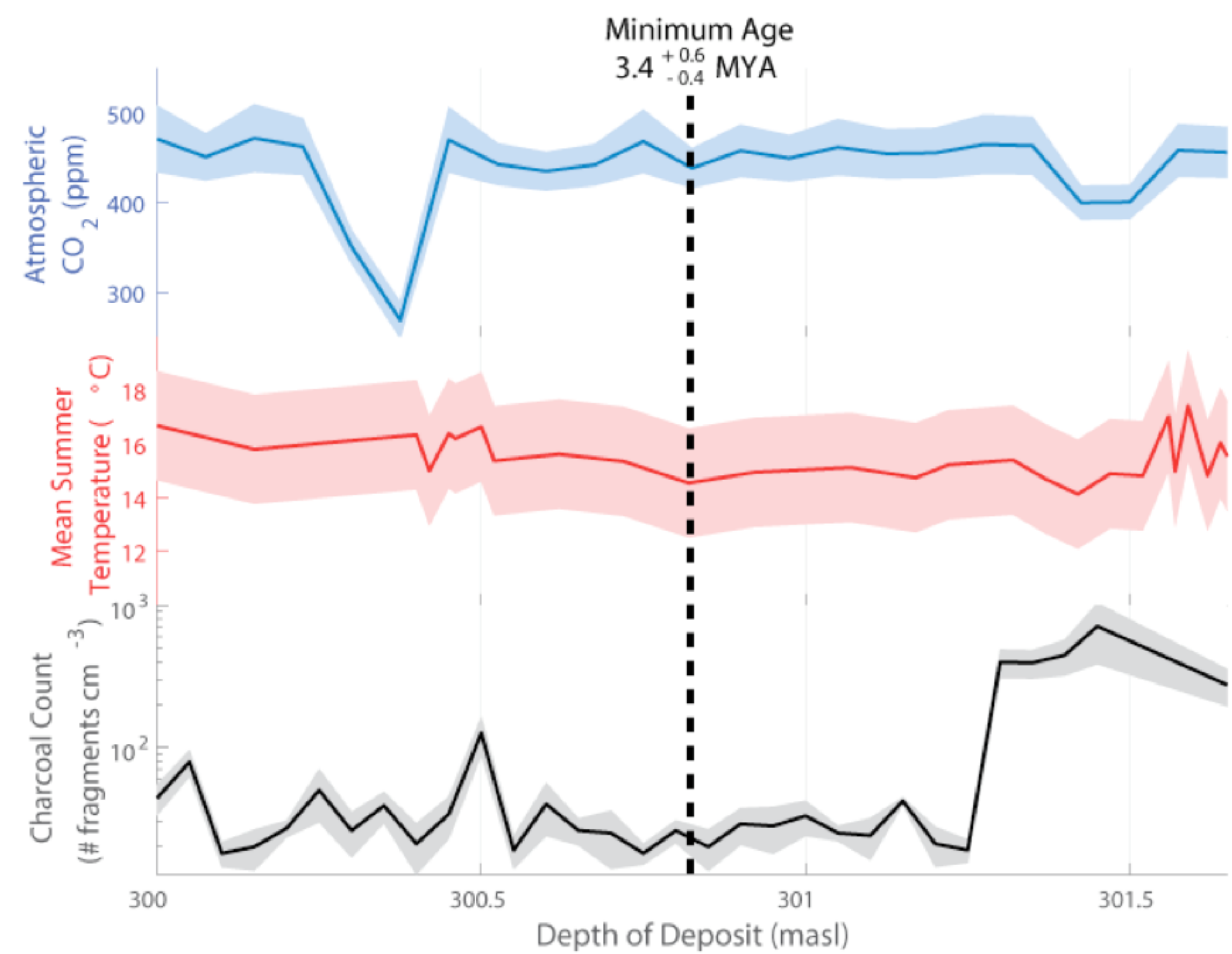

Preliminary data:

Fletcher et al. in prep 


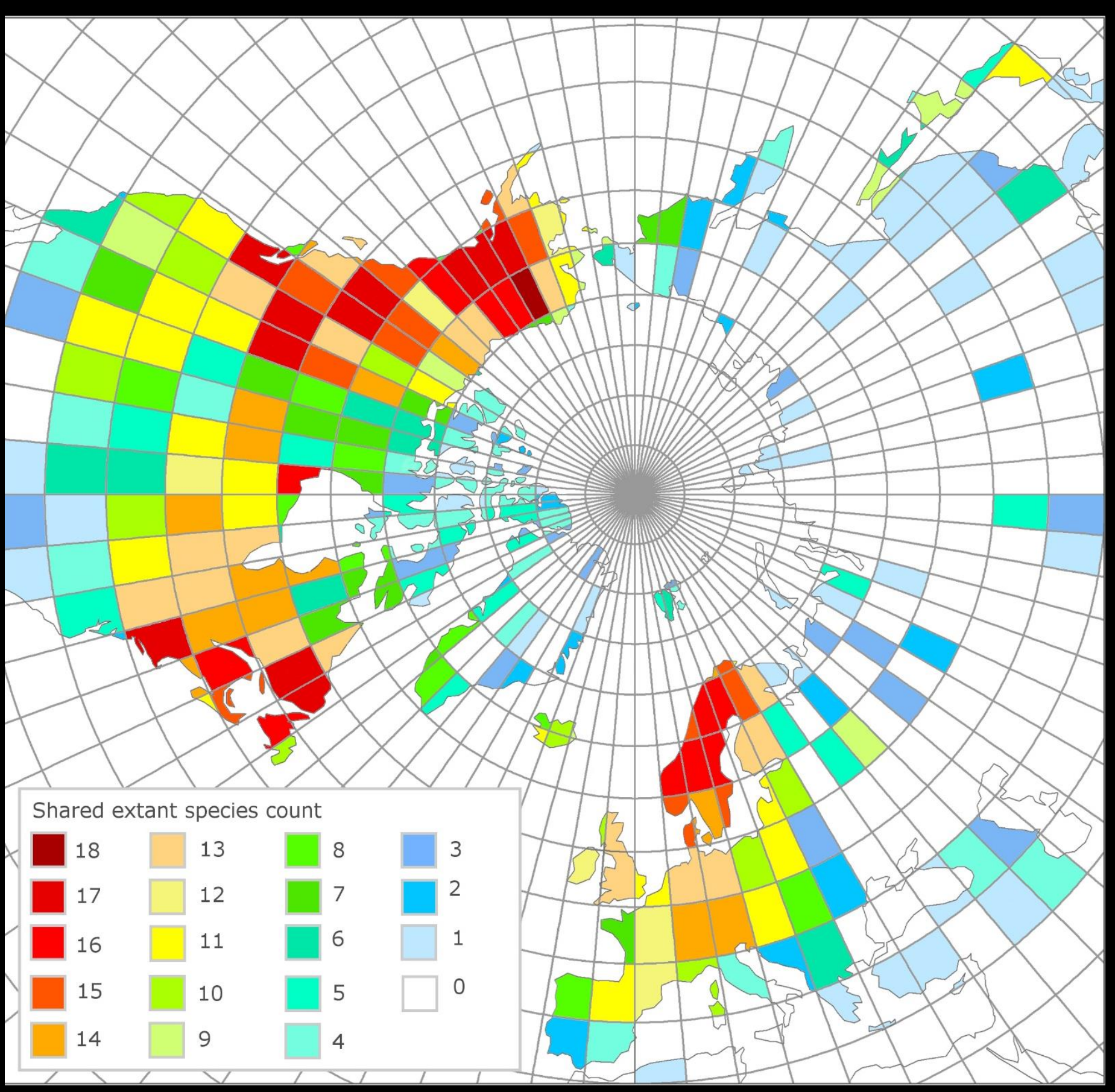

Fletcher et al. in prep 


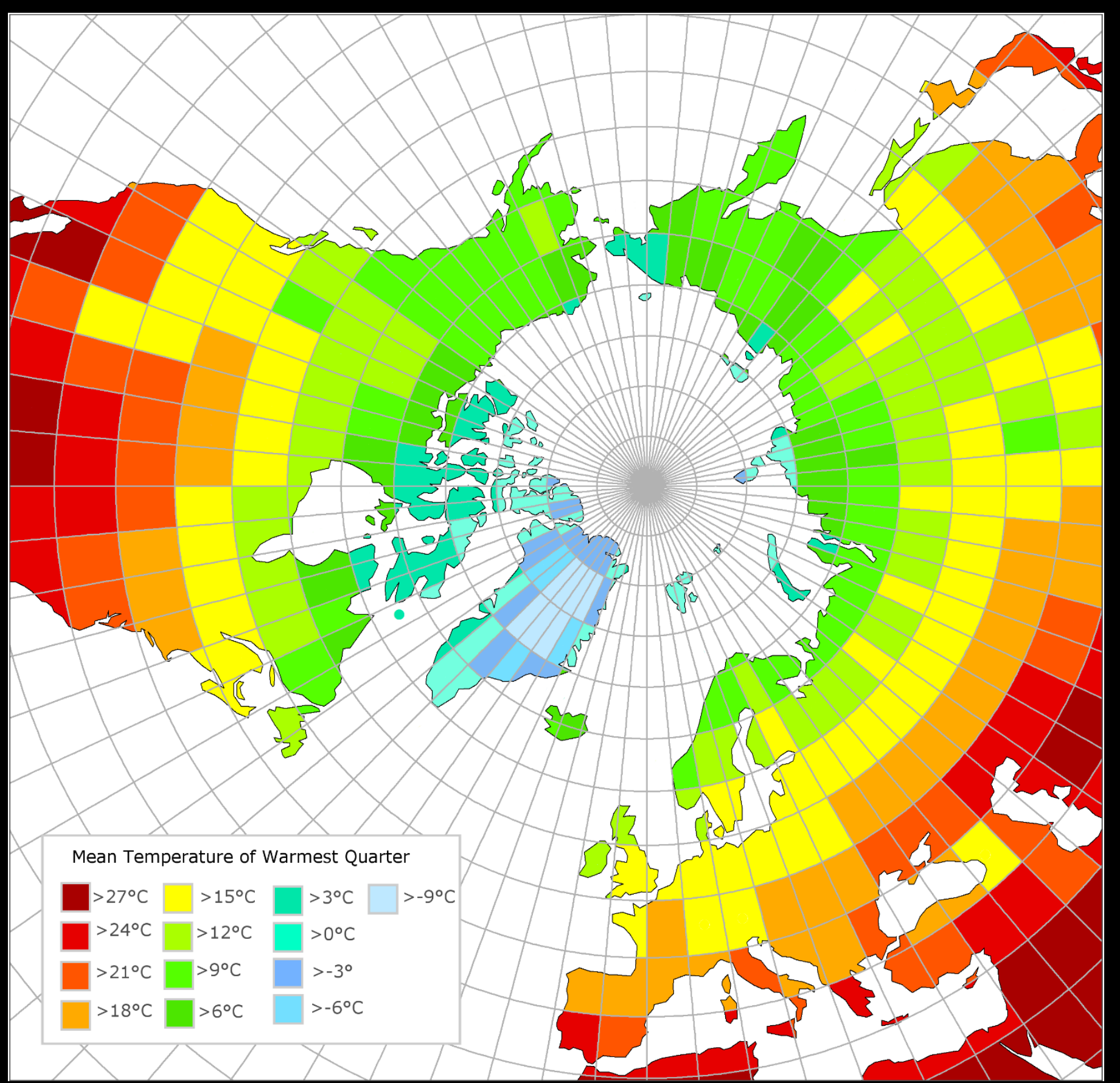

Fletcher et al. in prep 


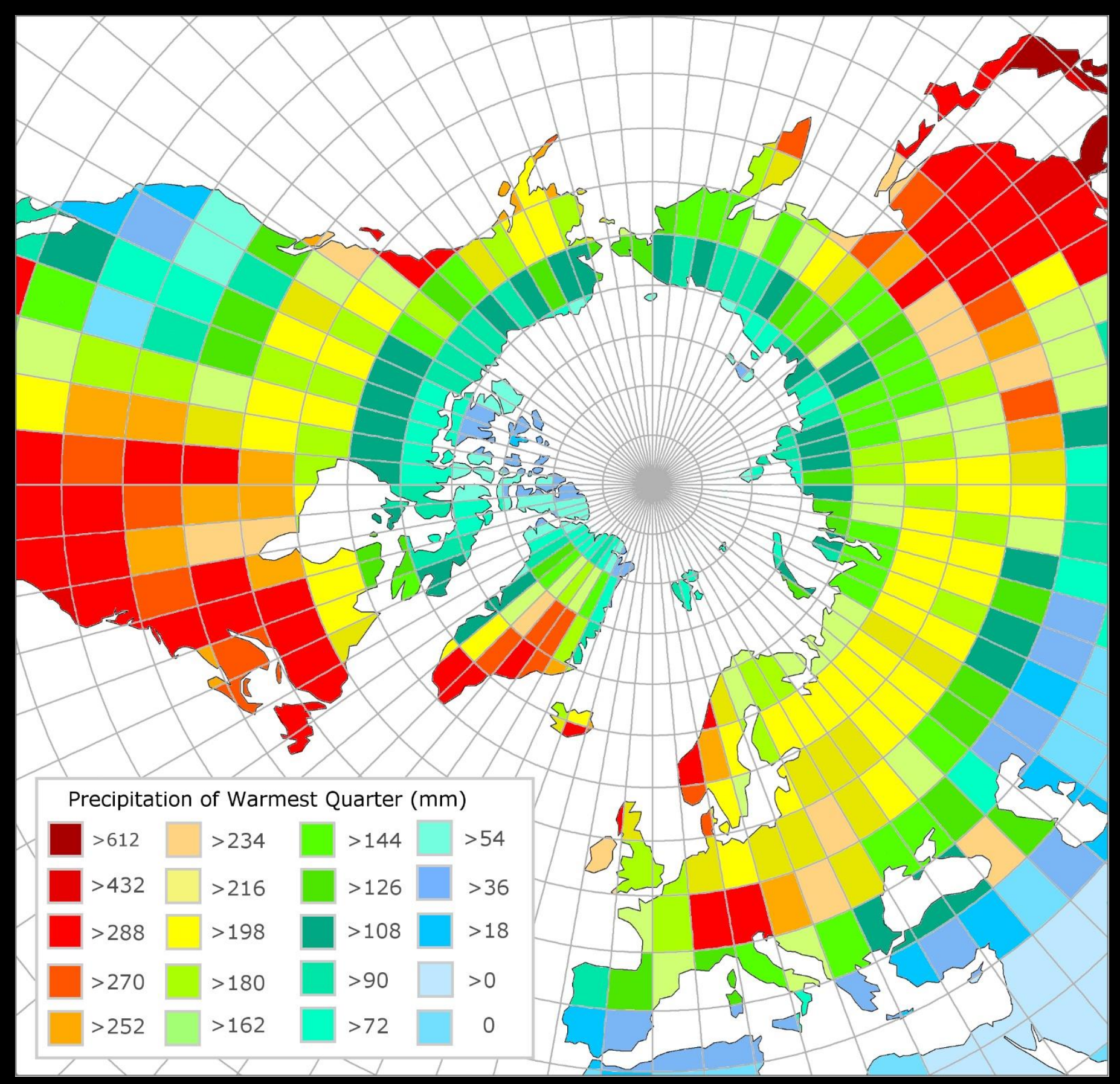

Fletcher et al. in prep 


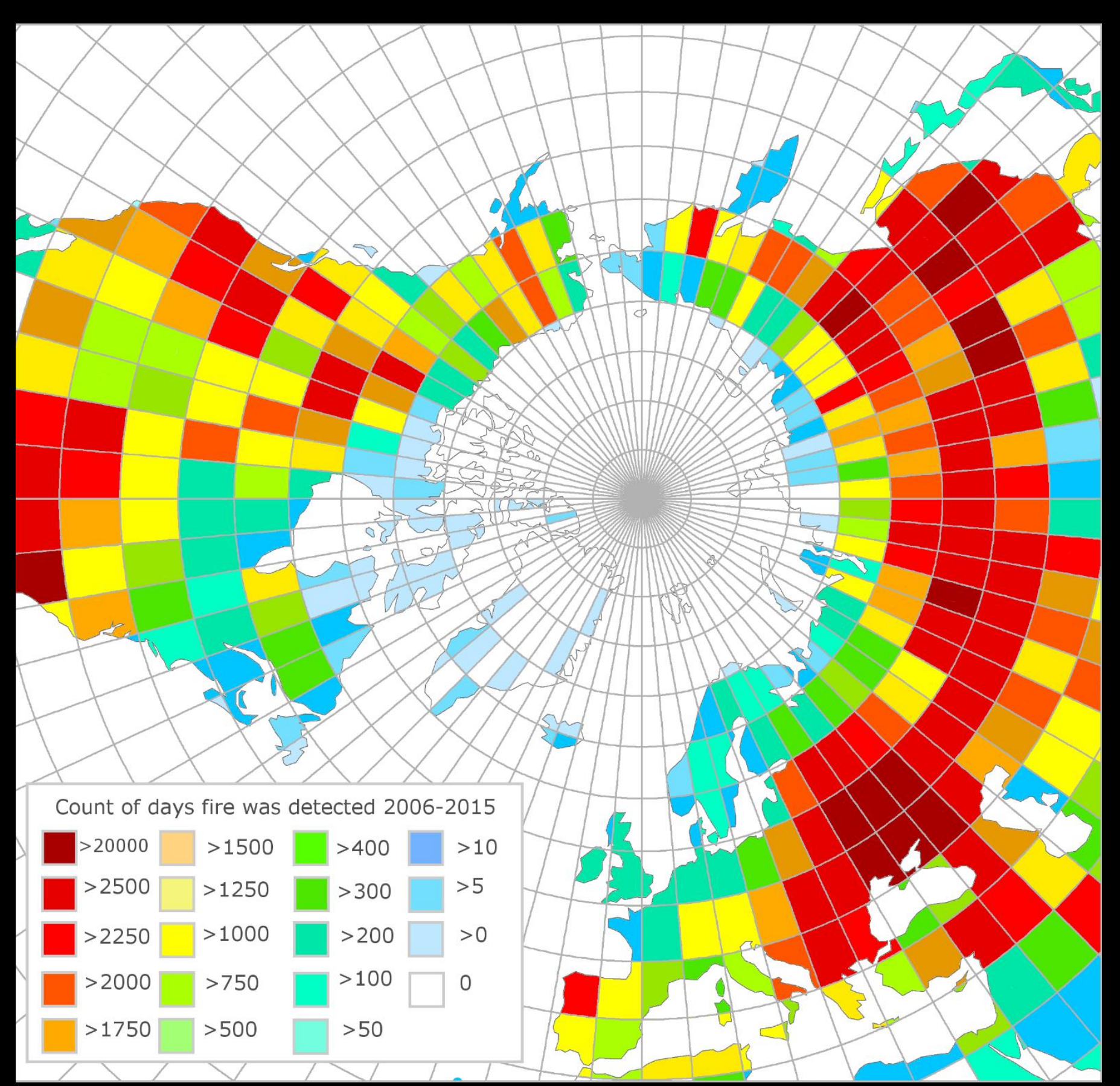

Fletcher et al. in prep 


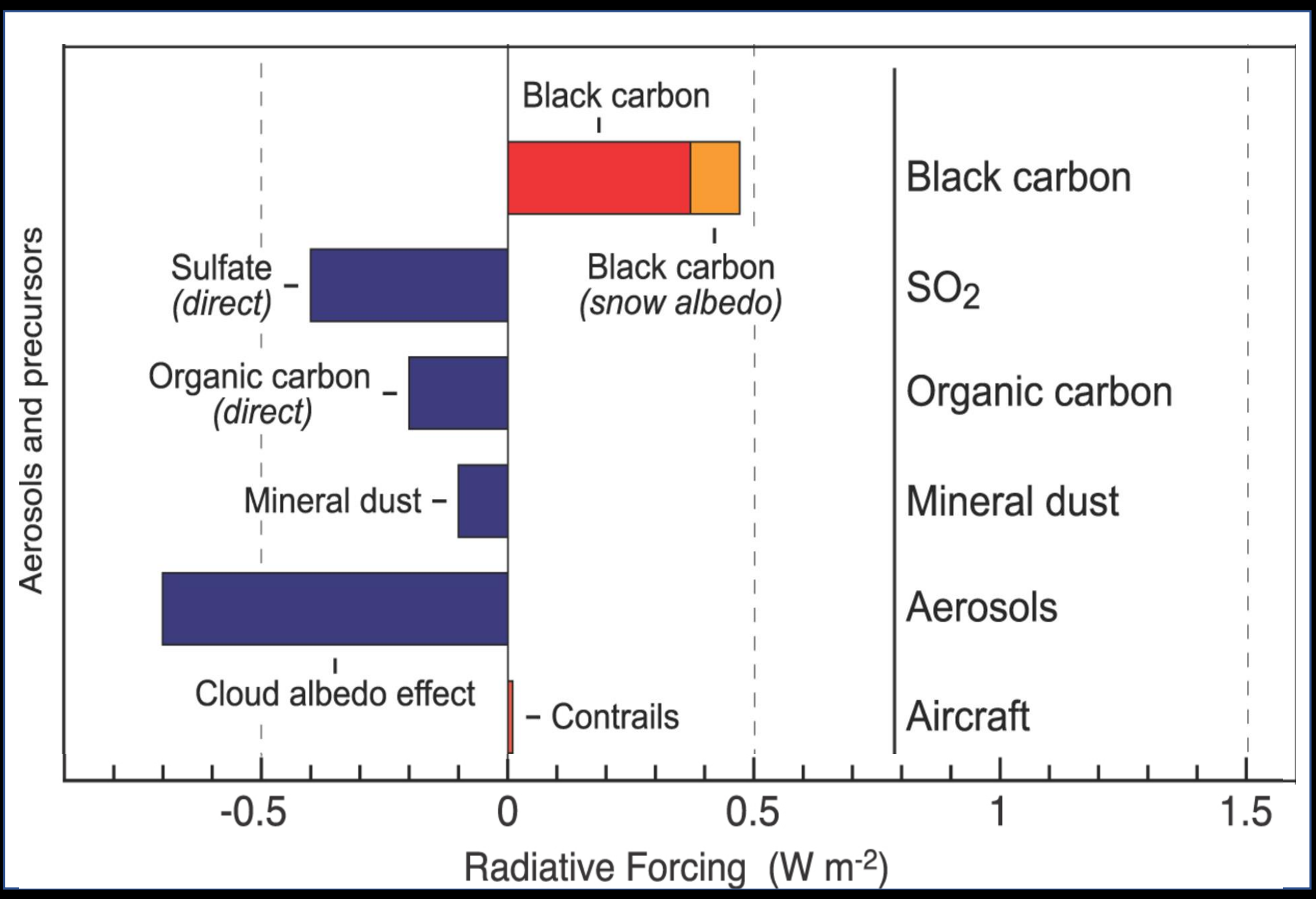

Feng et al. in prep 


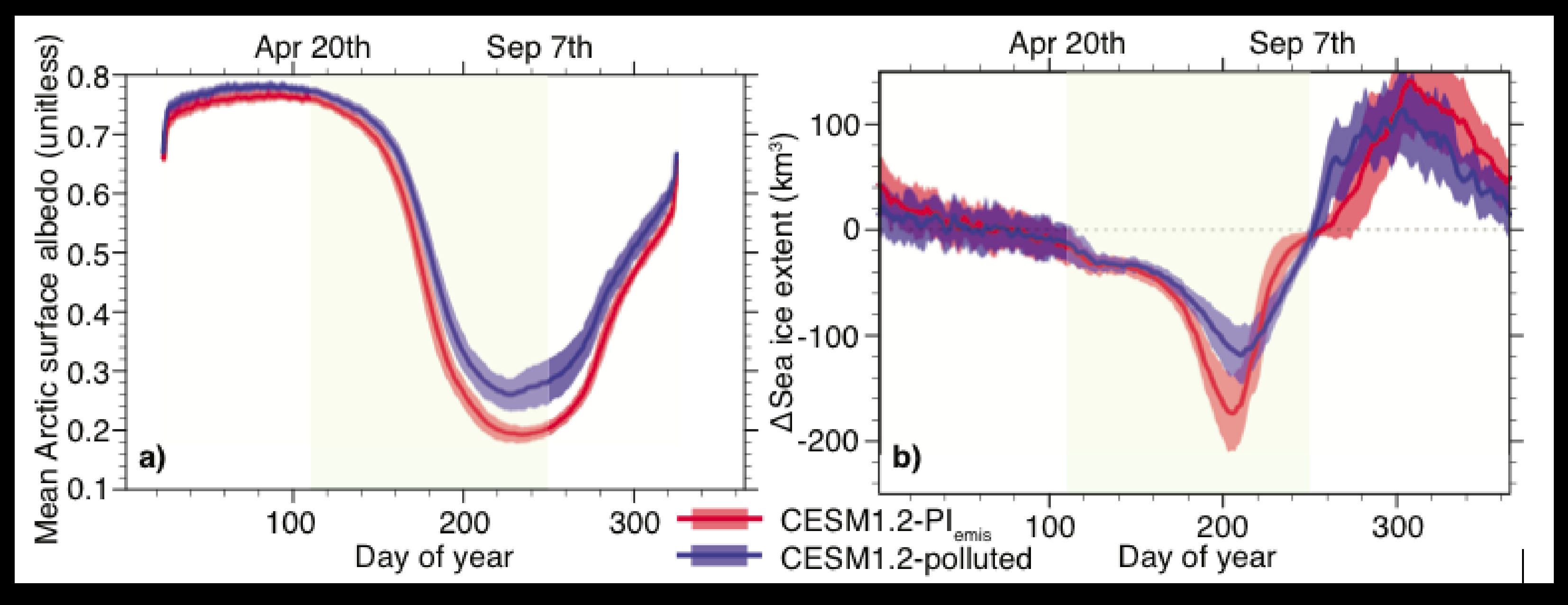


Key Findings

Fire was widespread geographically and temporally in the Pliocene Arctic

Fire has important effects on regional climate via interaction with vegetation, clouds, and sea ice albedo

The addition of long-term feedbacks improves proxy-model mismatch for the Pliocene Arctic 
Much still to do, including: 


\section{Pollen-charcoal high resolution study at Fyles' Leaf Beds}


Fire scar analyses

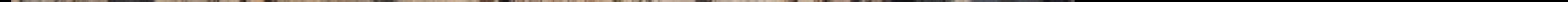


Improving black carbon effects in Earth System Models

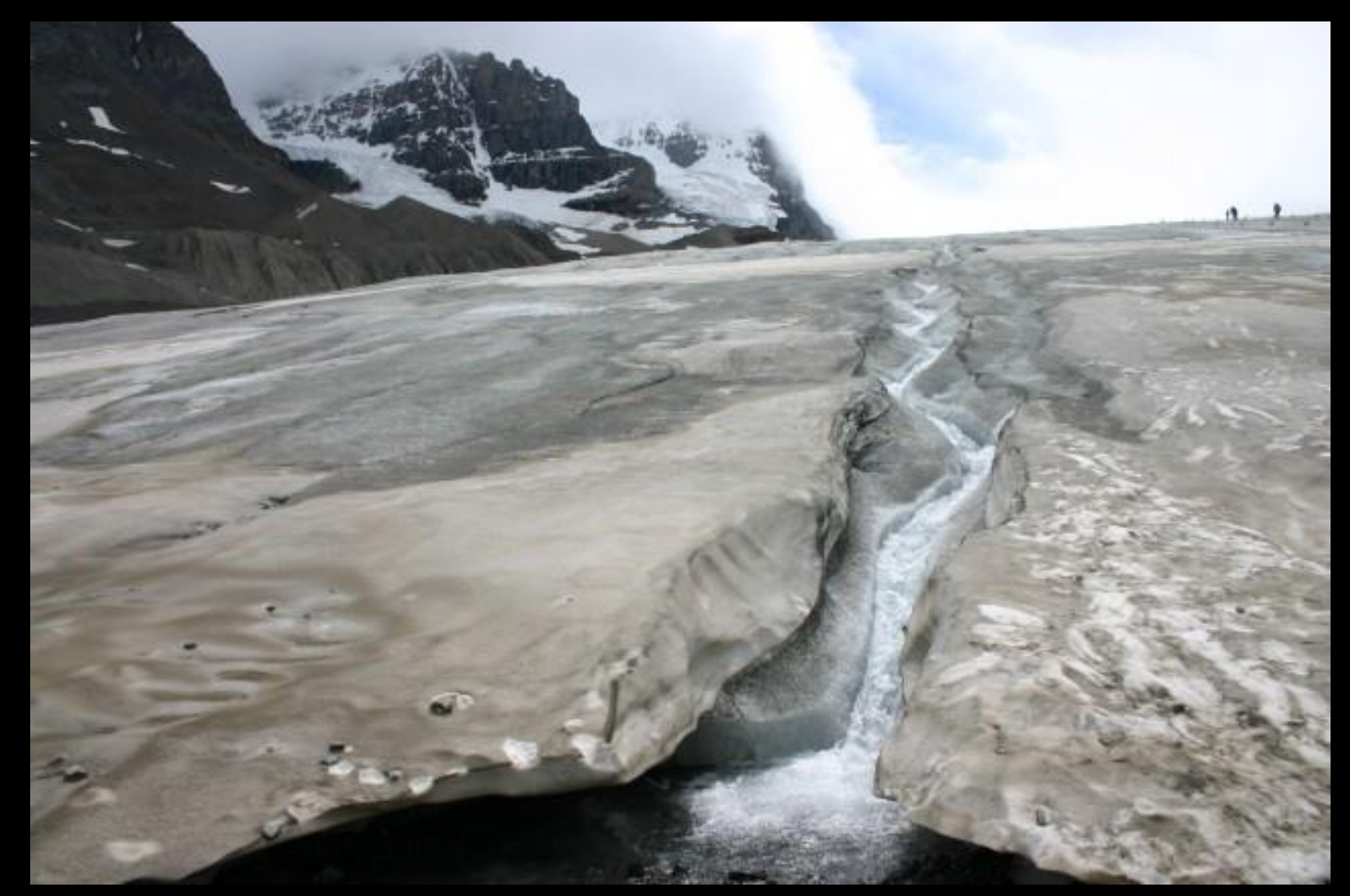




\section{Acknowledgements}

- Funding:

- National Geographic Committee for Research \& Exploration

- NSF Polar Programs

- Polar Continental Shelf Program

- Co-authors:

- Ran Feng \& Bette Otto-Bliesner (NCAR),

- Kendrick Brown (Natural Resources Canada),

- Lisa Warden \& Jaap Sinninghe Damste* (NIOZ Royal Netherlands Institute for Sea Research)

- Adam Csank (University of Nevada)

- Philip Higuera \& Ashley Ballantyne (University of Montana)

- Natalia Rybczynski (Canadian Museum of Nature)

- PoLAR-FIT Field Teams

\section{- Canadian Museum of Nature}

- Title image from Elk Bath by John McColgan.

*corrected from abstract and proceedings 